\title{
"Una impronta di italianitá": os livros didáticos para as escolas étnicas italianas no Brasil entre o liberalismo e o fascismo
} \author{
in Brazil between liberalism and fascism \\ en Brasil entre el liberalismo y el fascismo \\ Alberto Barausse \\ Università degli Studi del Molise (Italia) \\ https://orcid.org/0000-0002-8326-046X \\ http://lattes.cnpq.br/5545877149387438 \\ barausse@unimol.it
}

"Una impronta di italianitá": the didactic books for Italian ethnic schools

"Una impronta di italianitá": los libros didácticos para escuelas étnicas italianas

\section{RESUMO}

Este artigo pretende investigar o processo histórico das políticas de produção dos livros escolares adotadas pela classe dirigente italiana para as escolas no exterior a fim de oferecer uma contribuição para o entendimento das dinâmicas e complexas ações que têm caracterizado e acompanhado o desenvolvimento da escolarização e dos processos culturais e formativos, sobretudo identitários, dos colonos italianos no Brasil, entre a segunda metade do século XIX e a fim dos anos 30, do século XX. Os livros didáticos foram, desde o começo da experiência da unificação italiana, um instrumento fundamental para as classes dirigentes italianas que tinham por finalidade modernizar e, sobretudo, homogeneizar e uniformizar o ensino nas escolas em sentido nacional. No curso das décadas seguintes, a produção e a circulação dos livros didáticos aumentaram significativamente também em relação ao desenvolvimento das publicações escolares. A questão assumiu uma grande importância também quando os governos italianos promoveram uma nova política de expansão colonial e de emigração de massa para o exterior. Após a aprovação da lei com a qual o governo Crispi, no ano 1889, instituiu o sistema das escolas italianas coloniais e subsidiadas, se colocou o problema de quais livros didáticos introduzir nos países que recebiam emigrantes italianos e quais características os mesmos deveriam ter. $\mathrm{O}$ artigo enfatiza o processo de continuidade e descontinuidade das políticas e da produção de libros didáticos introduzidos nas escolas italianas no exterior e no Brasil, em específico até a ascensão do fascismo para fomentar diferentes ideias de italianidade.

Palavras-chave: Escolas italianas coloniais no exterior; Política pública do livro escolar; Etnia, identidade nacional e educação. 


\begin{abstract}
This paper aims to examine the development of the textbooks' policy defined by Italian ruling class for the schools into abroad between the second half of XIX Century and the decade of thirties of XX Century. The article offers a contribute to the reconstruction of the complex dynamics, which characterized the development of schooling, the cultural and educational processes in the formation of the identity of the Italian settles during the same period in Brazil. From Unification, the textbooks were a fundamental tool of the Italian ruling elite that introduced and promoted a centralized control to support efforts of nationalization, modernization and homogenization of teaching in the schools as in the national as into abroad context. Over the years, production and circulation of textbooks increased. After the beginning of new colonial and new emigration policies by Prime Minister Francesco Crispi, in the 1889, along the approval of the Reform of Italian schools system in the abroad, ministerial authorities sought to establish the textbooks authorized in the teaching. The paper focus on the evolution and discontinuity of the Italian textbook policies until the fascism era, when new textbooks were introduced in the Italian schools into abroad to support a different ideas of "italianess".
\end{abstract}

Key words: Italian colonial schools into abroad; policy of textbook; Ethnic-identity, national identity and education; emigration and education to Brazil.

\title{
RESUMEN
}

Este trabajo se pretende profundizar en el desarrollo de las políticas del libro escolar establecidas por la clase dirigente para las escuelas italianas en el exterior entre la segunda mitad del siglo XIX y la década treinta del siglo XX. El artículo quiere ofrecer una contribución para reconstruir las dinámicas complejas que han caracterizado y acompañado el desarrollo de la escolarización y de los procesos culturales y formativos, sobre todo identitarios, de los colonos italianos en Brasil en el propio período. Los libros didácticos fueron, desde el comienzo de la experiencia de la unificación italiana, un instrumento fundamental para las clases dirigentes italianas que tenían por finalidad modernizar y, sobre todo, homogeneizar y uniformizar la enseñanza en las escuelas en sentido nacional. En el curso de las décadas siguientes, producción y circulación de los libros didácticos aumentaron significativamente también en relación al desarrollo de las publicaciones escolares. La cuestión asumió una gran importancia también cuando los gobiernos italianos promovieron una nueva política de expansión colonial y de emigración masiva hacia el exterior. Desde el momento posterior a la aprobación de la ley con la que el gobierno Crispi, en el año 1889, instituyó el sistema de las escuelas italianas coloniales y subsidiadas, se planteó el problema de qué libros didácticos introducir en los países de colonización y cuáles características debían tener. El artículo enfoca la evolución y la discontinuidad de las políticas y de la producción de los libros didácticos introducidos en las escuelas italianas en el exterior y en el Brasil en el específico hasta el fascismo para fomentar las diferentes ideas de italianidad.

Palabras clave: Escuelas italianas coloniales en el exterior; Política pública del libro escolar; Etnia, identidad nacional y educación; emigración y educación en Brasil. 


\section{Introdução}

Na história da educação italiana as pesquisas realizadas durante as últimas décadas sobre os processos culturais e formativos que interessaram às comunidades de italianos residentes no exterior ficaram isoladas. Os estudos conduzidos até hoje se limitaram a oferecer uma visão sintética sobre a questão, seguindo algumas linhas fundamentais: o eixo ideológicopolítico, o legislativo e, parcialmente, também o eixo quantitativo das escolas italianas no exterior. No que tange a específica realidade do Brasil, dispomos de investigações conduzidas por alguns estudiosos brasileiros que, no panorama do papel assumido pelas etnias e por movimentos sociais na história da educação, começaram a evidenciar as dinâmicas mais significativas em torno das instituicões escolares e dos processos de escolarização dos italianos em regiões do Brasil, sobretudo nos territórios onde chegou a primeira colonização italiana, caso do Rio Grande do Sul. Ainda mais escassos são estudos sobre culturas de escolas, de práticas de ensino, processos de escolarização e formação da identidade; análise que a historiografia da educação internacional como os estudos de Julia, Novoa, Viñao Frago, Escolano Benito e Sani - sugerem investigar.

Para a análise da história das políticas dos livros escolares foram mobilizadas diversas fontes. De um lado, foram utilizados os documentos produzidos para o Ministério das Relações Exteriores a partir do fundo arquivístico - Arquivo Escolas - que conserva cartas e documentos sobre o trabalho das diferentes comissões, além dos títulos dos livros distribuídos nas escolas subsidiadas ou governativas. Esses documentos foram cruzados com outros relatórios, como as relações de editais e escritas de cônsules ou agentes consulares, que mostram a complexa realidade escolar do Brasil. As fontes arquivísticas foram cruzadas, também, com outras normas e regras que o governo italiano estabeleceu entre 1861 e 1943, relativo às escolas italianas no exterior e publicadas no Boletim do MAE (Ministeiro dos Negócios do Exterior). Por fim, o mesmo valor conservam os periódicos dos professores e as revistas pedagógicas os quais oferecem muitos vestígios para o debate.

\section{A política do livro escolar na Itália após a Unificação}

No dia seguinte à constituição da Unificação, os objetivos do crescimento dos níveis de alfabetização do povo italiano e da sua escolarização, premissas necessárias ao processo de construção da identidade nacional, acabaram por empenhar a classe dirigente liberal (Morandini, 2003) e nesse contexto, os livros textos constituíram um instrumento fundamental na mais complexa estratégia voltada a dar vida a um eficiente sistema escolar e educativo público (Porciani, 1982, 1983; Chiosso, 2000).

$\mathrm{O}$ controle dos livros de leitura e dos manuais escolares destinados à escola representou um instrumento de particular significado no quadro das políticas escolares e educativas dos primeiros governos após a Unificação. O governo da Itália unida, como aqueles do Piemonte pré-unificado - atribuíram esta importante tarefa ao órgão institucional mais próximo, o Ministério da Instrução Pública e o Conselho Superior da Instrução Pública (de agora em diante CSPI). Não ao acaso, o artigo 10 da lei Casati, ou seja, da "Carta Fundadora" do ordenamento escolar, previa que o Conselho Superior da Instrução Pública examinasse e propusesse à aprovação do ministro, os livros e os tratados destinados às escolas públicas.

O objetivo dos ministros que guiaram a Instrução Pública nos primeiros dez anos após a Unificação foi o de assegurar o caráter unitário e a uniformidade de destino dos livros de texto usados junto às escolas de cada nível e grau. É necessário perceber que com a Lei Casati abriu-se, progressivamente, caminho para o estabelecimento, até aquele momento existente no Reino da Sardenha, da adoção de um único texto para as escolas elementares. Muito cedo, de 
fato, nos ambientes ministeriais e junto à classe dirigente liberal, amadureceu a ideia que a maior liberdade no uso dos livros se deu de forma mais eficaz no novo contexto nacional, caracterizado pela presença de várias tradições locais. Como lembra Giovanni Antonio Rayneri em 1865, na relação sobre o estado da instrução pública pela parte relativa à Instrução elementar e normal.

Um livro ótimo para algumas escolas destinadas a um povo, ou melhor dizendo, aos professores de diversas índoles e de diversas culturas, não alcançará tanto, ou pelos menos, será declarado como tal, suscitará chamamentos por parte de outro povo ou, melhor dizendo, por parte de outros professores que simpatizam com outros autores (Consiglio Superiore, 1865, p. 543).

Desde os primórdios da introdução do sistema escolar casatiano, todavia, o exame preventivo dos livros de texto encontrou dificuldades correlacionadas, em primeiro lugar, com a falta de uma vontade política em efetuar uma sistemática verificação dos livros de texto. Também se defrontou com as ambiguidades de uma legislação que deixava brechas de interpretação, com os limites organizativos dos órgãos delegados a tal tarefa e, por último, com os crescentes interesses dos editores escolares e do mercado editorial (Porciani, 1982, 1983). Logo, perfilou-se um verdadeiro conflito de competência entre o ministro da Instrução Pública e o seu órgão consultivo (CSPI) de um lado e os membros descentralizados (conselheiros escolares provinciais) de outro. Um conflito destinado a estimular, após a reforma da administração escolar de 1867 pelo ministro Michele Coppino, que atribuía aos membros administrativos descentralizados, os conselheiros escolares provinciais, a tarefa de preparar as listas de livros escolares autorizados para uso em salas de aula. Assim, se criou um duplo canal de avaliação, uma vez que o Conselho Superior da Instrução Pública, não perdia as suas prerrogativas que, confirmadas pelo provimento, reorganizava o Conselho Superior da Instrução Pública, sinalizando a atribuição da tarefa de examinar os livros de texto à comissão anual, composta por cinco membros eleitos, no CSPI.

Em 1876, com o começo da experiência da esquerda histórica, o ministro Coppino, quis dar continuidade às escolhas sustentadas pelo antecessor Ruggiero Bonghi e retomou, assim, a orientação voltada a sinalizar ao CSPI o exame dos livros de texto. No início dos anos 1880 a situação relativa ao manual escolar e aos livros em uso nas escolas italianas, parecia profundamente mudada a respeito do quadro de vinte anos anteriores da fase da unificação. Como observava Pasquale Villari, pela "grande especulação livreira feita em toda Itália", por alguns editores escolares do Norte, que tinham abertamente aproveitados da objetiva fragilidade das empresas editorias do Centro-Sul e das Ilhas, como também, das condições sufocantes que marcavam o mercado livreiro, se passou a uma especulação direta feita em cada província. Um fenômeno, um tanto quanto alarmante, na opinião do historiador meridional, em base do qual eram colocadas as carências e as ambiguidades de uma normativa que permitia um grande espaço à interpretação e assegurando, de fato, "ampla e ilimitada liberdade no uso dos livros de texto". Acabara por induzir parte dos conselheiros escolares provinciais a exercer na sede local "uma vigilância de pura forma". Tal fenômeno impedia o alcance de um dos objetivos de fundo perseguido pela classe dirigente nacional desde os primeiros anos na década de 1870, ou seja, a criação de um sistema escolar realmente unitário e de um, "ensino nacional", conduzido "com algumas normas gerais e com uma orientação pedagógica uniforme" (Nota 6 de abril de 1880).

Diante da insatisfação pelos resultados, os responsáveis pelas políticas educativas mudaram, posteriormente, as orientações. Entre 1881 e 1883, o ministro Baccelli, primeiramente, reformou o CSPI e, depois, instituiu uma Comissão Central à qual confiava a "dupla função em definir os critérios necessários para a escolha dos livros de texto" e em 
"formar um elenco daqueles aprovados" (Decreto Ministerial de 17 de agosto 1881). Os objetivos para os quais era constituída a Comissão Central era garantir uma maior uniformidade dos livros adotados nas escolas italianas e em colocar um freio na generalizada prática em mudar as adoções sem uma válida razão, o que representava uma verdadeira e própria pedra no sapato de tantas famílias. Através de tal escolha, todavia, o ministro operava uma verdadeira e própria centralização do sistema, o qual, até àquele momento, tinha sistematicamente implicado no processo de decisão, os conselheiros escolares provinciais e os mesmos colegas dos docentes das escolas secundárias. $\mathrm{O}$ desenvolvimento das políticas do livro escolar foram favoráveis entre o fim dos anos 1880 e os primeiros anos de 1890, primeiros anos do governo Crispi e do ministro da Instrução Pública, Boselli, procurando colocar ordem no "emaranhado", solicitando aos membros da administração escolar mais descentralizados, os conselheiros escolares provinciais, que recolhessem listas dos livros usados nas escolas (Barausse, 2008, p. 48).

\section{Os livros escolares para as escolas italianas no exterior entre 1888 e 1916}

Foi neste período que passou a amadurecer a ideia da produção de livros destinados às escolas italianas ao exterior. No quadro mais complexo do projeto Crispi, voltado a construir um estado forte e uma política externa de potência (Levra, 1992; Duggan, 2000), se voltaram, também, para a inauguração de uma nova política de emigração e a reorganização das escolas italianas no exterior. O nacionalismo crispino olhava a emigração como fator de força expansionista da Itália e das relações comerciais (Salvetti, 2002). A reorganização das escolas se colocava no mais geral da instrução nacional e civil, apoiando os valores patrióticos e a construção de uma imaginação coletiva fundada no culto da pátria. A presença das instituições escolares no exterior assumiu características diversas em relação aos países de diferentes destinos dos fluxos migratórios. Os objetivos estabelecidos pela nova lei de reorganização foram perseguidos através da distinção entre escolas governativas e escolas subsidiadas com financiamento por parte do Ministério, destinado e gerido através de autoridades consulares (Floriani, 1974). Exatamente porque orientadas à finalidade de serem "estimuladoras da educação nacional e do sentimento patriótico" (As escolas italianas nas colônias da América, 1889-1890, p. 207), as escolas tinham que acatar aos programas governativos, oportunamente adequados em algumas circunstâncias territoriais. Também o uso dos livros de texto voltou a ser o centro de atenção. O Ministério das Relações Exteriores definiu em colaboração com o Ministério da Instrução Pública, um elenco dos livros que podiam ser utilizados nas escolas.

Os anuários publicados entre o final dos anos 1880 e a metade dos anos 1890, permitem, de fato, recuperar pistas significativas da produção editorial tida como adequada para as escolas italianas no exterior. No estado atual da pesquisa foi possível comparar a publicação de uma primeira lista para o ano escolar de 1888-1889, subdividido entre as escolas técnicas e ginasiais para as quais indicava 19 títulos, as escolas elementares masculinas e femininas e as escolas noturnas, para as quais marcava complexamente 83 títulos (Ministero, Annuario 1889). Limitando a nossa análise somente ao âmbito das escolas elementares podemos constatar que a produção livreira indicada refletia, em parte, a reforma dos programas que, como é sabido, foi publicada em 1888 e acompanhada pelas 'educações gerais' redigidas por Aristide Gabelli para favorecer a modernização do complexo didático nas escolas através da mais sistemática introdução aos princípios do positivismo (Reforma, 1888). Para as escolas elementares eram, assim, indicados silabários e complementos, como aqueles de Giuseppe Toti (1887 e 1889), ou da inspetora florentina Emilia Costetti Biagi (1876; 1889), editados já antes da reforma, mas fundamentados nos métodos mais inovadores para favorecer a aprendizagem simultânea da escrita e da leitura, através de um sistema 
graduado, fônico e ilustrado, introduzido desde os anos 1870 (Barausse, 2014). Ou mesmo, próximo às leituras de Pietro Dazzi, das quais se fez abundante uso nos primeiros dez anos após a Unificação. Se evidenciam textos que cumpriam mais com os novos programas, como o livro de leitura do diretor de uma das maiores e mais lidas revistas para professores, Gabriele Gabrielli, autor de 'Os primeiros afetos' (1888), ou aqueles de Maria Viani Visconti (1887) e de Ida Baccini (1887) (Ministero, Annuario, 1889, p. 189-190). Para o ensino de história, geografia e educação cívica prevista sobretudo nas classes elementares superiores $\left(4^{\mathrm{a}}\right.$ e $5^{\mathrm{a}}$ ) os autores indicados nos anuários faziam referência aos testes de Giovanni Merighi (1888, 55 ed.) ou aquele de Camilo Randazzo (1884 e 1886), de Luigi Vugliano (1886), Silvio Pacini (1889), Pietro Valle (1888). Se para o ensino da gramática os únicos nomes indicados eram aqueles de Raffaello Fornaciari e Giovanni Colombini, para aqueles de matemática estão os tradicionais de A. e C. (1888) e o texto de Maria Grillo Orlandini (1889) para as classes femininas. O quadro era complementado por testes de ensino da administração doméstica ou por aquele de desenho através dos livros de Ilario Tarchiani (1872) ou de Giuseppe Boidi para as escolas femininas (Ministero, Annuario, 1889, p. 189-190).

Não estamos ainda em condições de documentar se a listagem de livros publicada no anuário de 1889 foi resultado do trabalho de revisão conduzido pela Inspetoria Central do Ministério das Relações Exteriores (MAE) no verão daquele mesmo ano, mas encontramos indícios presentes junto ao arquivo histórico diplomático. A necessidade de adequar os programas escolares àqueles emanados para as escolas deslocadas no território nacional, tinha induzido o Ministério das Relações Exteriores a instituir uma comissão especial que teria se reunido em agosto de 1889. A preocupação do responsável pelo órgão de controle do MAE não foi o de produzir relevantes modificações, mas prevenir o ativismo do mundo editorial para procurar adequar ao prescrito. Por isso, a inspetoria central apressou-se em comunicar ao subsecretário para "fazer o menos possível quanto às mudanças nos livros de texto já adotados no ano escolar recentemente decorrido" e de evitar fornecer comunicações, comissões ou contatos aos livreiros e aos editores para evitar despesas inúteis" (Nota de 12 de julho de 1889).

Em 1892, o Ministro das Relações Exteriores procurou promover um processo parcial de revisão dos livros escolares. À luz das experiências conduzidas, as quais havia revelado que "os livros de texto adotados em uma escola colonial, nem sempre respondem às necessidades e ao caráter especial de uma outra quando, também, sejam ambas do mesmo grau" o responsável enviava às escolas coloniais da bacia do Mediterrâneo, o convite para começar um exame mais atento dos livros em uso. Particularmente, pedia aos diretores e aos professores para que avaliassem a idoneidade dos livros, levando em conta os seguintes critérios:

a) Se o livro de texto, tanto pela facilidade e pela clareza da exposição, quanto ao conteúdo, seja adequado, ou não, ao estado de inteligência e das cognições que possam supor-se ao aluno que entra na classe colonial na qual o livro é adotado. b) Se o livro satisfaz quanto possível, aos objetivos almejados pelos alunos, dando a eles atitudes e condições especiais do país onde esses moram. c) Se o livro, considerados os costumes locais, a forma de governo e as condições religiosas dos habitantes, não contenha nada que vá ofender ou causar desprazer às famílias dos alunos, às populações em geral ou às autoridades locais verso a qual, seja por débito de hospitalidade, seja no interesse mesmo da escola se devam lealmente e dignamente afirmar os mais delicados resguardos. (Circular de 10 de 1892). 
A exigência em repensar a produção livreira e pela carência de controle (Barausse, 2008, p. 65 e seguintes), induziu o ministro a solicitar a revisão e a publicação de novas listas de livros de texto. Uma primeira foi publicada no anuário de 1897 (Ministero, Annuario, 1897, p. 73-67). Um segundo elenco de livros foi produzido em 1899, aos cuidados do ministro das Relações Exteriores (Ministero, Elenco, 1899). Esta lista de livros, resultava muito mais completos e orgânicos com relação às indicações fornecidas nos anos precedentes. O ministério predispôs uma lista de livros destinados às escolas elementares masculinas, às escolas elementares femininas, às escolas noturnas, às escolas complementares, às escolas técnico-comerciais e comerciais, às escolas ginasiais e secundárias. Quantitativamente o número de textos era decididamente inferior àquele previsto para as escolas do território nacional. No que diz respeito às escolas elementares masculinas e femininas, os textos indicados eram, respectivamente, de oitenta e oito a setenta e cinco títulos. Esta produção foi, depois, integrada com aquela destinada às escolas noturnas, composta por 14 títulos. A maior parte dos títulos dizia respeito aos livros de leitura que para as classes elementares masculinas e femininas eram, respectivamente, 50 e 34 produzidos, respectivamen te por 39 e 34 autores. Para as escolas noturnas a lista indicava 7 títulos de leituras. O elenco dispunha, no entanto, de títulos também para o ensino da caligrafia, a partir da segunda série, da gramática, da aritmética, da geografia, da história da pátria, da língua francesa a partir da quarta série, do desenho para a quinta série (Ministero, Elenco, 1899). Os elencos publicados nos anuários de dois anos sucessivos apresentavam um crescimento anterior do ponto de vista quantitativo. Os títulos indicados para as escolas elementares remontavam a 108 e 109 produtos, sempre do mesmo número de 81 autores. (Elenco, 1899-1900; Elenco 1900-1901). A produção livreira refletia, apenas parcialmente, as solicitações que derivavam da aplicação de novos programas publicados pelo ministro Baccelli em 1894 e da nova produção avaliada pelas comissões sediadas no Ministério da Instrução Pública entre 1894 e 1897 (Tabacchi, 2013). Tanto o primeiro, quanto o segundo elenco, compreendiam textos já indicados sete anos antes, com novos livros que respondiam às exigências dos novos programas.

Para as primeiras séries elementares, junto ao nome de Pietro Dazzi e Gabriele Gabrielli, sobressaiam os silabários e os relativos complementos escritos por Siro Corti e Pietro Cavazzutti (1895) seja para as escolas masculinas, seja para as femininas, publicados pelo editor milanês Vallardi, junto àquele de Augusto Alfani $\left(1897,8^{\mathrm{a}}\right.$ ), enquanto, nas escolas permaneciam os textos de Gabrielli e Dazzi, considerados ainda válidos. Mas, também para a terceira série se introduzia como livro de leitura Il Frugolino, escrito pelo chefe da administração provincial da Escola de Estudos de Roma, Carlo Tegon (1897), junto aos livros 'Letture' de Ida Baccini (1894). Para as quartas e quinta séries, junto à Nova Gramaticazinha de Fornaciari (1897), e a de Luigi Ferrari (1891, 2), de Cesare Mariani (1896) e de Luigi Morandi e G. Cappuccini (1895), se previa o uso do Minuzzulo de Collodi, que como autor aparecia também entre as indicações para a quinta série com Il Giannettino, junto ao livro Cuore de De Amicis. A Antologia poética de Camilo Randazzo completava o quadro das leituras. Para o ensino da história e da geografia, além dos livros de leitura de Bacci e Gotti pelo título Le Glorie da Patria (1897), era indicado o texto de Pietro Valle. (Ministero, Annuario, 1897, p 63-66; Ministero, Elenco, 1899). A leitura de Giuseppe Castelli (1896 e 1897) juntamente com aquele de Giacomo Veniali (1898), e de Francesco Paolo Scaglione e Filipponi (1899) e de Mestica (1898) que integravam a nova edição do volume de Corti e Cavazzuti (1897), juntamente com aquele de Augusto Alfani (1898), de Tegon (1898) e de Dazzi (1898) para a mesma classe. O ensinamento da leitura e da escrita era complementado por testes de caligrafia, por aqueles que davam como referência os 
clássicos métodos de Boscary e de Cobianchi. Mas ricas eram as indicações relativas às leituras de história e de geografia. De fato, além do livro de leitura de Bacci e Gotti eram indicados também os de Francesco Bertolini (1896), Onorata Mercanti Grossi (1894) e Giovanni Soli (1895) com o texto de geografia de Pietro Valle (1895). As leituras eram, pois, completadas por textos para o ensino de aritmética e de desenho assegurados pelos volumes de Bordiga (1895), de Frattini (1898), de Pincherle (1894) e de Palazzi, além daqueles para o ensino do francês (Novelli, 1896).

As mudanças nas orientações nas políticas nacionais do livro escolar condicionaram também as escolhas do Ministério das Relações Exteriores. Sucessivamente às decisões do ministro da Instrução Pública, Orlando, para colocar fim à experiência das comissões centralizadas para a avaliação e a revisão dos livros de texto para todo os dez anos precedentes, o Ministério das Relações Exteriores, através da Inspetoria Geral, se colocou o problema de como "chegar a uma total recopilação" do elenco dos livros de texto (Promemoria de 13 outubro 1905). Os documentos, todavia, não confirmam a presença de uma nova lista de livros produzida em seu interior. A definição das orientações em matéria de livros de texto se tornou mais complexa nos anos sucessivos. Por um lado, se aproveitou as iniciativas do Ministério da Instrução Pública e Ministério das Relações Exteriores e, por outro lado, do Ministério das Colônias, instituto em 1912, para assegurar a produção de livros a serem adotados nas escolas da bacia do Mediterrâneo, nos países sob o direto controle colonial, como a Tripolitânia e a Cirenaica, também livros a serem distribuídos nas escolas italianas geridas diretamente pelo governo, presentes também na bacia Mediterrânea, seja, por fim, nas escolas subsidiadas no outro lado do oceano. Foi solicitado às comissões especiais a aprovação de livros, a serem usados nas colônias, livros "que, além da conformidade com os ditames da técnica pedagógica, seriam escritos com especial atenção à forma de pensar dos alunos das escolas coloniais, especialmente os indígenas e que visassem as necessidades orgânicas do ambiente colonial" (Contini, 1932, p. 148). Contudo, as empreitadas bélicas e aquelas, mais específicas, ligadas à reorganização dos serviços escolares das colônias não permitiram o funcionamento da comissão até 1921 . Durante esta fase se tolerou a escolha feita nos institutos, individualmente, pelos docentes, sem qualquer controle da administração central na Itália.

\section{Do fim da Primeira Guerra Mundial à ascensão do fascismo}

Logo após o final da Primeira Guerra Mundial, retomaram com vigor os programas e debates sobre o papel das escolas italianas no Exterior na promoção da língua e da cultura nacional. No quadro da retomada das iniciativas, em apoio do progresso da presença das escolas italianas no exterior, o ministro das Relações Exteriores voltou a recuperar um papel ativo através da Direção Geral das Escolas Italianas no exterior que, a partir de 1920, através da guia do estudioso Ciro Trabalza, favoreceu a redefinição de um programa de ação que teve um olhar particular nas instituições escolares e culturais nas Américas. (Barausse, 2015). Neste contexto, no seio do Ministério das Relações Exteriores, em 15 de janeiro de 1921, foi instituída a Comissão Especial que começou a aprovar alguns manuais (ASMAE, 1922, Contini, 1932, p. 148). No Ministério das colônias, ao invés, a comissão Especial para exame dos manuais foi reconstituída com o Decreto de 10 de abril de 1921. A primeira das duas comissões foi composta por cinco componentes. Além do presidente, o docente da Universidade de Roma, Cesare De Lollis, fazia parte Francesco Piola e Riccardo Truffi, além dos inspetores centrais do Ministério da Instrução Pública, Roberto Gruppioni, vice-diretor didático das escolas comunitárias de Roma e Giovanni Ferri, régio docente 
do Instituto Técnico de Roma. A escolha sobre a presidência caiu em De Lollis, por que Trabalza apreciava as suas competências no âmbito da literatura moderna e especialmente na literatura francesa "cujo ensino tem uma importância especial nos institutos médios e nas escolas elementares de italianos no exterior."

Em 26 de fevereiro de 1922, quando ainda a comissão não tinha ultimado os trabalhos, a Direção Geral lançou o elenco dos livros aprovados e daqueles não aprovados para as escolas elementares. O diretor convidava os responsáveis das sedes consulares a transmitir "reservadamente" a nota aos diretores das escolas, para não começarem os elencos, e de valer-se destes somente no caso em que alguns professores tivessem desistido em adotar os livros de texto não aprovados pela comissão. O elenco previa vinte e cinco títulos de silabários, primeiras leituras e outros livros, quatro títulos de gramática e um manual de educação moral, seis títulos de história e geografia, nove manuais de aritmética e geometria (Lista, 1921). Não conhecemos as razões para tal escolha. Os trabalhos da Comissão não tiveram, porém, uma significativa continuidade, sobretudo, devido algumas mudanças na sua composição (Barausse, 2015). Depois de um ano e meio de trabalho, De Lollis comunicou, de fato, não poder continuar o trabalho como presidente e pediu demissão. Inicialmente foi chamado outro docente da Universidade de Roma, o italianista Vitorio Rossi para substitui-lo, mas ele não aceitou o cargo. Em sua substituição, Trabalza referendou o nome de Pietro Fedele. A escolha do docente de História Moderna considerou os méritos científicos, mas também pelo seu "vivo sentimento patriótico" como consta a prescrição escrita à mão e indicada por Trabalza no decreto. Mas também, por haver melhor credibilidade, legitimidade e por dispor de maior facilidade para interagir com a sede ministerial.

Percorrendo os títulos de livros autorizados na circular das escolas italianas do exterior podemos registrar mais elementos de descontinuidade do que de continuidade na definição e circulação dos livros escolares. De fato, as listas publicadas entre o fim do oitocentos e início do novecentos, encontramos o nome de Siro Corti e Pietro Cavazzutti e aqueles relativos aos pequenos volumes para as diversas classes elementares realizadas por Mestica Galamnini, entre o nome de Tarra que se ligava à tradição imediatamente pré e pós-unitária. Só aparentemente nova, porém, era a presença de títulos que pertenciam a uma produção pré-bélica. Ligados principalmente aos anos de experiência política giolitiana, em particular às mudanças dos programas de inspiração herbatiana de 1905, eram, de fato, a maior parte dos livros escolares indicados na lista. Alguns reeditados após o fim da Primeira Guerra Mundial, mas concebidos e produzidos durante o período precedente ao advento, como os de Libero Ausoni (1905; 1920), Giuseppe Celli (1920), ou aqueles feitos por professores, publicitários e editores de jornais, renomados diretores de associações de professores e, em alguns casos, não apenas Ciarlantini e Capodivacca (1905), Giovan Battista Curami (1905), Irlandi e Nolleti (1906), Guido Antonio Marcati, Alfredo Plata e Luigi Arnaud (1914) estavam indicados. Expressões da produção concomitante ou imediatamente sucessiva da guerra, ao invés, eram as leituras de Leopoldina Zanotti (1915), Saverio Fino e Felice Mattana (1916), Virgilio Brocchi e Andrea Gustarelli (1920), Emilia Formiggini Santamaria, Marcellina Cappelli Baiocco (1920) ou leituras especificamente produzidas para exaltar o mito dos mortos na Primeira Grande Guerra e destinados às escolas italianas no exterior como a leitura de C.L. Guelfi ou textos realizados especificamente para as escolas italianas no exterior - como de fato precedente - aquele de Giovanni Di Giusto e Francesco Pasciuti (1921).

Ao lado dos livros destinados ao ensino da escrita e da leitura, foi apresentada para o ensino gramatical com os textos de Capodivaca, Adalgisa Costa, Giuseppe Poli e C. Perniciaro (1914) aos quais também foram acrescentados também uma gramática portuguesa 
para escolas italianas criada por Carlo Parlagreco (1919). Também para o ensino de educação moral ou de história e geografia, a lista incluía muito poucos títulos, seis apenas, incluindo aqueles de figuras bem estabelecidas no cenário editorial italiano. Juntamente com o geógrafo Giuseppe Ruggero, autor de volumes produzidos desde o final da metade do século XIX e com edições subsequentes apropriadamente adaptadas aos programas de 1905, era indicado o nome de Eugenio Comba, autor de um texto de Atlas, muito difundido e produzido no início do novecentos. Esses textos foram acompanhados pelas Lições de Geografia e História para as classes elementares superiores criadas por alguns professores das escolas municipais de Turim. O de Giovanni Rossi, 'Contos de História Pátria', inicialmente publicados após os programas de 1905, foram revisitados em uma nova edição em 1916, retomando e simplificando para as escolas elementares os cursos destinados ao ginásio inferior. Ou livros de escritores e escritoras famosos como Olga Visentini que, após alguns anos, teve também a aprovação pela comissão presidida por Giusepe Lombardo Radice (SANI e ASCENZI, 2008, pp. 131-132). Ainda, o de Luigi Di San Giusto, um livreto produzido em 1915, no contexto da grande campanha de mobilização civil para explicar às crianças as razões da entrada da Itália na Guerra e que, portanto, refletia o clima nacionalista do pós-guerra (Barausse, 2015).

Apesar da disponibilidade de um maior número de títulos, a produção parece que não satisfez as necessidades dos alunos italianos que viviam no exterior. Como escreveu, em uma longa memória, o diretor Alemanni, responsável no Ministério, no final da década de 1920, esses textos tinham que ser "algo mais e diferente". Além de educar o homem, eles deveriam visar preparar aquele cidadão italiano, que vivia no exterior, ou seja, que tinha que se adaptar às necessidades locais, que em muitos casos foi levado à cidadania do país hospitaleiro, ao mesmo tempo ele deveria manter seus laços firmemente enraizados com sua Pátria de origem e senti-la, em todos os momentos, em seu coração, e exaltando-a na presença de estranhos, amando-a e servindo-a em pensamento e obras fiéis (Relator Alemanni, 1923).

Naquele período, para solicitar a produção de livros mais adequados para as escolas italianas no exterior, as autoridades ministeriais, além das comissões, recorreram a providências específicas como editais publicados pelo Ministério da Instrução Pública para produção de novos manuais a serem adotados nas escolas italianas no exterior e em territórios coloniais. O primeiro procedimento foi um edital para escrita de um livro de história pátria, a ser adotado nas escolas de ensino fundamental e cursos livres no exterior, seguido por um para leitura; posteriormente, um edital para realização de manuais para ensino fundamental da Tripolitania e Cirenaica.

Com o primeiro se queria favorecer a produção de um livro que, por um lado, seguisse às disposições dos programas governamentais para o ensino da história nas escolas de ensino fundamental e, por outro lado, alimentasse desde a infância o sentimento nacional. Um texto patriótico capaz de

dar uma ideia adequada daquilo que o mundo deve à Itália: não depositório de erudição, mas sim, plenitude de informação, não emaranhado de nomes e datas, mas segurança de orientação cronológica, não acúmulo de conceitos, mas larga compreensão dos múltiplos e complexos elementos da vida histórica, não ênfase, mas chama contida de paixão e fé, capaz de fomentar nas tenras mentes dos leitores o orgulho de ser e sentir-se italianos (Barausse, 2008, p.1331).

O segundo edital, de dezembro de 1921, instituía um prêmio para promoção da escrita de um livro de leitura a ser usado no ensino fundamental no exterior. A obra, a ser realizada em cinco volumes, devia corresponder aos programas previstos nas escolas 
do Reino, adaptadas às condições particulares para motivar os alunos indígenas, que frequentavam escolas italianas. O texto não apenas daria conta das diferenças de hábitos e de comportamentos entre gênero masculino e feminino, mas também dos distintos ambientes "especialmente para as regiões mediterrâneas e para as Américas", especificado, sobretudo

a contribuição trazida pelos nossos grandes e humildes trabalhadores para o desenvolvimento e incremento da civilidade no mundo, para todos os temas e para todos os lugares, de maneira que, nas crianças italianas, viventes em países assim variados e distantes entre si, o sentimento de nacionalidade seja alimentado e tornado mais forte por uma fé consciente na grandeza da pátria (Barausse, 2008, p.1332).

O terceiro edital pretendia promover a escrita, sobretudo, de textos de leitura para as seis séries do fundamental destinados a Tripolitania e Cirenaica, para os quais o ministério indicou critérios que expressavam um nacionalismo mais moderado através de uma abordagem pedagógica que pretendia dar conta de tradições e das culturas locais. Assim, por exemplo, os autores eram convidados a evitar na escrita "todos os traços de caráter confessional e também juízos morais ou aqueles exemplos que [poderiam] ofender sentimentos e práticas de hebreus e muçulmanos" assim como lhes era solicitado evitar "manifestações de patriotismo que [seriam] ineficazes com alunos não italianos"; ou, ainda, eram solicitados nos contos ilustrar como protagonistas não apenas crianças italianas "mas também, por vezes, indígenas", e de fomentar nos alunos "o recíproco afeto e respeito, apesar das diferenças profundas de nacionalidade, de raça, de confissão e de costumes" (Barausse, 2008, p. 1335-1336).

Essas foram ações que, de qualquer modo, anteciparam as mudanças do clima cultural e pedagógico que, no ano sucessivo, levaram à nova proposta das iniciativas ministeriais, com a instituição da comissão para a revisão dos manuais. A primeira, presidida por Lombardo Radice, inauguraria uma época breve, mas intensa, que através do trabalho das comissões posteriores presididas por Vidari, Giuliano, Romano e Melchiori, com o intento de particularizar o manual escolar fascista, determinariam uma mudança significativa no panorama editorial escolar italiano (Ascenzi, Sani, 2009).

Em $1^{\circ}$ de outubro de 1924 , foi publicada nova portaria com programas que intentavam condicionar a tipologia dos produtos editoriais destinados às escolas italianas no exterior. Eles foram pensados para a função específica da escola italiana no exterior destinada a assumir um papel fundamental, em contextos marcados por diferenças linguísticas, religiosas e culturais, mesmo assim destinados a condicionar os sotaques nacionalistas em sentido moderado (Oriani, 1926, p. 86). Um papel fundamental foi colocado nos livros de leitura para os quais os programas davam algumas indicações bem precisas:

A escolha do livro de leitura para as escolas no exterior é como nunca delicada. O livro de texto deve ter amplas referências à vida das nossas longínquas colônias, deve exaltar o sentimento e o amor à Pátria, sem por isso, ofender as outras nacionalidades, deve mostrar desta a beleza, os monumentos antigos e novos, as formas mais grandiosas de civilização e de atividade, fazendo com isso, que sejam conhecidos os homens mais representativos e lembrando o esforço imane na recente guerra nacional (Oriani, 1926, p.93) 
O fruto desta primeira etapa foi diferenciado pela produção de textos orientados a favorecer a transmissão de modelos educativos fundamentados no orgulho das tradições culturais italianas e, ao mesmo tempo, na capacidade de ser bons cidadãos nos vários países, dentre os quais o Brasil. O seu uso e a sua distribuição, eram considerados indispensáveis e fundamentais pelas autoridades consulares para a recuperação e a conservação étnica identitária, no momento no qual a tendência prevalente em diversos países, inclusive no Brasil, parecia ser da "desnacionalização". Livros como os de autoria de Francisco Pasciuti e de Giovanni Di Giusto, intitulado "Cuore Lontano" (Coração Distante), editado pela Mondadori em 1922 (Pasciuti, Di Giusto, 1922), ou aquele de Alarico Buonaiuti, editado pela Bemporad em 1925 (Buonaiuti, 1925). Os livros de Buonaiuti foram propagados na segunda metade dos anos vinte, pois para chegar à conclusão dos trabalhos das primeiras publicações foram necessários três anos. Somente em 2 de dezembro de 1925, seis meses após a entrega do relatório por parte da comissão, Mussolini anunciava oficialmente o êxito negativo para o livro de história e o êxito positivo para dois dos cinco volumes de leitura de Alarico Buonaiuti. (Relatório Boselli, s.d. mas de 1924, ASMAE, AS, 1923-1928, b. 537).

\section{Da segunda metade dos anos 1920 ao fim de 1930, a modo de conclusão}

A partir do fim dos anos vinte, foi delineando-se a circulação de livros de texto produzidos na Itália com o objetivo de corresponder mais eficazmente às exigências da propaganda ideológica e da pedagogia nacional fascista/mussoliniana a fim de assegurar a formação do italiano novo no exterior (Gentile, 2002, La Rovere, 2002, pp. 51-58). A produção destes novos textos adaptava-se à estratégia dos responsáveis fascistas voltada a introduzir, nos países de forte presença italiana, uma maciça propaganda destinada a produzir o 'italiano novo' auspiciado pelo fascismo; a consolidar o papel das escolas como instrumentos de suporte à política externa do fascismo, sempre mais orientados, a obter a aprovação dos imigrantes junto às outras iniciativas como viagens e visitas de imigrantes na Itália, a organização das colônias de verão, as formas de enquadramento dos jovens (Pretelli, 2010, p. 123-138).

A exigência foi advertida em amplos setores da realidade cultural e educativa fascista e foi expressa também na circular emanada pelo Ministério das Relações Exteriores em 31 de outubro de 1927, por dispor um novo edital de concurso entre os cidadãos italianos residentes na Itália e no exterior, para a publicação de um livro educativo intitulado "O italiano de Mussolini". A iniciativa promovida e financiada pelo cônsul geral Labia e da esposa em memória do "odioso atentado parricida", tinha o objetivo de assegurar a redação de um texto que contribuísse para "dar e infundir nessa gente, cada classe de hábitos e noções [de] vida civil, não só, mas também, sentimentos patrióticos, religiosos humanitários, qual [o] Duce mesmo pode desejar (telegrama de 2 de novembro de 1926). Substancialmente se tratava da redação de um texto que indicasse a representação do novo espírito criador depois do advento do fascismo no povo italiano e deveria ser, no conjunto, um guia para os jovens, aos quais indicaria a via para formar completos e perfeitos italianos do amanhã. Esse deveria ser o livro do espírito, da idealidade e da vida fascista e deveria dar aos italianos de cada classe a clara visão daquilo que deve ser o italiano novo, as características, os sentimentos, os destinos (Telegrama de 14 de outubro 1927).

Os reflexos destas primeiras mudanças encontram-se nos volumes para o ciclo completo das escolas de ensino fundamental, elaborados por Vera Gaiba em colaboração com Francesco Lanza, produzidos entre os anos 1927 e 1928, e por Giuseppe Locatelli e Arturo Mondovì publicado em 1928 pela Mondadori (Barausse, 2015). 
As mudanças da produção editorial combinaram-se com outras mudanças significativas, reflexo das novas estratégias dos vértices político-administrativos fascistas a partir das mudanças na administração das escolas italianas no exterior. Em 1928, depois do fechamento do Comissariado para a emigração, foi instituída a nova Direção Geral dos italianos e das Escolas no Exterior, a qual foi confiada à gestão de Piero Parini. A figura de Parini é paradigmática na mudança de perspectiva: ele, de fato, era o secretário dos fascios italianos no exterior. A nomeação, provavelmente, era para assegurar uma maior fidelidade dos vértices ministeriais no endereço mussoliniano, e foi seguida por uma série de medidas destinadas a afetar também a produção editorial. Através da nomeação de Parini e a mudança da estrutura destinada a administrar, seja os italianos, seja as escolas no exterior, foi promovido, segundo quanto afirmado por Pretelli, "uma progressiva avaliação de poderes para a gestão da italianidade no exterior" e a progressiva politização do mundo da emigração e dos institutos escolares fora da Itália (Pretelli, 2010, p. 133).

Levando em conta a lei de janeiro de 1929 que introduzia o livro único de Estado para as escolas de ensino fundamental, no âmbito do Ministério da Educação Nacional, como se sabe, foi instituída uma comissão que, em poucos meses, conseguiu redigir os textos para as duas primeiras séries do ensino fundamental. Contemporaneamente foi instituída uma comissão, junto ao Ministério das Relações Exteriores, para garantir a elaboração de novos livros de texto confiando a tarefa a um grupo de autores préselecionados pelo mesmo Ministério. Este organismo conseguiu trabalhar com uma "Fascística rapidez", como relembra o seu presidente, e aprovar uma série de livros de leitura a serem destinados às escolas italianas no exterior e às colônias. Todavia, o responsável pela direção geral, apelando para os interesses da nação, achou por bem propor a unificação das duas comissões, criando assim uma mista, Ministério da Educação Nacional e Ministério das Relações Exteriores (MEN e MAE) para atender o objetivo da complementação e adaptação dos textos para as escolas de ensino fundamental já realizadas para as escolas do Reino. O trabalho a ser feito não era muito simples:

a adaptação será razoavelmente fácil no que se refere às ciências em senso lato (aritmética, geometria) mas será mais delicada e complexa no que se refere às disciplinas histórico-morais [...] Estas disciplinas possuem caráter formativo e devem ser usadas em textos que sejam adaptados às necessidades especiais e à organização das escolas italianas no exterior e que levem em conta as condições ambientais nas quais se desenvolve a ação destas escolas evitando, contudo, de esbarrar na sensibilidade político-religiosa local. É, de fato, conhecido nestes últimos tempos o sentimento de nacionalidade em alguns Estados, em especial da bacia do Mediterrâneo, tenha sido exasperado, de tal maneira que a atividade das escolas estrangeiras se desenvolve em meio a suspeitas e com dificuldades de todos os tipos [...] um trabalho de adaptação e, às vezes, de reformulação (Relatório P. Parini, 6 de junho de 1930).

No que se refere aos textos para as escolas de Ensino Médio, Parini sugeria a reconstituição da comissão já instituída em 15 de janeiro de 1921 que, porém, não havia tido muitas ocasiões de se encontrar, aprovando somente alguns textos, considerados, além disso, ultrapassados visto que já havia acontecido o fascismo. Para este fim indicava a oportunidade de integrar a comissão com os três inspetores centrais para as escolas de Ensino Médio do Ministério da Educação Nacional (Ibidem). 
Neste contexto surgiram alguns dos livros de texto único de Estado destinados a serem utilizados para o ensino da leitura e da escrita, no ensino de várias disciplinas nas escolas italianas no exterior ou nas colônias; um processo que tornou-se também editorial com a instituição de editora específica da Direção Geral dos Italianos e das Escolas no Exterior (Pretelli, 2010, p. 163-165). Para alguns livros, sobretudo aqueles de leitura ou para os subsidiários, são mais facilmente identificáveis os autores. Entre esses estão enumerados os volumes para as Leituras por Clementina Bagagli, os livros de leitura para a segunda série de Giuseppe Fanciulli, autor também de Leituras de Religião (Letture di Religione), as Leituras para a terceira série de um autor não identificado, ou o livro de leitura para a quarta série compilado por Paolo Monelli, e as leituras para a quinta série intitulado Sole d'Italia. Em 1937, foi editado um novo livro de leitura compilado por Milly Dandolo junto à reedição de precedentes livros de leitura, entre os quais a nova edição dos volumes de Bagagli dos quais foi possível analisar aquela de 1941. Os autores dos textos para o ensino das diversas disciplinas, ao invés são mais dificilmente identificáveis, com exceção aquele redigido pelo professor Dante Giromini do ensino elementar, que se tornou diretor do Instituto Magistral de Carrara em 1930 e que compilou uma gramática editada pela Direção Geral Italianos no Exterior, em 1935.

Além dos novos textos indicados pela comissão, no caso do Brasil houve difusão das monografias específicas para um desenvolvimento dos conteúdos ao fascismo intransigente. Entre esses podemos citar o texto organizado pela Direção dos Italianos no Exterior intitulado Quando il mondo era Roma (Quando o mundo era Roma), além daqueles ilustrados por Paolo Monelli no volume intitulado La tua Patria (A tua Pátria), publicado pela editora Mondadori, editora próxima ao regime. Ou as leituras de Guerriero Bemporad, Piccoli italiani nel mondo (Pequenos italianos no mundo), volumes nos quais as referências diretas ao fascismo são ainda mais diretas. Estes textos ressaltam, além das características do novo homem fascista enquadrado na representação nacionalizante da Itália através da ênfase do mito de Roma como portadora de civilização e cultura contra os povos bárbaros, a insistência sobre o perigo ex terno e os inimigos funcionais à formação de uma mentalidade hipernacionalista, acompanhada pela exaltação do perfil do ditador como salvador da Pátria. Neste contexto foi publicado o livro de Gioacchino Volpe, com o título Fatti degli italiani e della Italia (Feitos pelos italianos e da Itália). Estes textos, alguns anos depois, seriam acrescidos pela antologia de literatura latina, dirigida, sobretudo, às Escolas Médias, cuidadas diretamente por Piero Parini (Barausse, 2015).

\section{REFERÊNCIAS}

ASCENZI A., SANI, R.. Il libro per la scuola tra idealismo e fascismo. L'opera della Commissione centrale per l'esame dei libri di testo da Giuseppe Lombardo Radice ad Alessandro Melchiori (1923-1928). Vita e Pensiero: Milano, 2005.

ASCENZI A., SANI R.. Il libro per la scuola nel ventennio fascista: la normativa sui libri di testo dalla riforma Gentile alla fine della seconda guerra mondiale, 1923-1945. Macerata: Alfabetica, 2009.

BARAUSSE, A. Il libro per la scuola dall'Unità al fascismo. La normativa sui libri di testo dalla legge Casati alla Riforma Gentile (1861-1922). Macerata: Alfabetica. 2 vol. 2008. 
BARAUSSE, A. Learning to read and write in Italy in the second half of the nineteenth century. Primers and reading exercise booklets: publications, ministerial control and teaching (1861-1898). History of Education \& Children's Literature, IX, (2), 109-149, 2014.

BARAUSSE, A. Os livros escolares como instrumento para a promoção da identidade nacional italiana no Brasil durante os primeiros anos do fascismo (1922-1925). In.: Anais. VIII Congresso Brasileiro de Educação. Universidade Federal de Maringá: Maringá, 2015, p. 1-15. https://doi.org/10.1590/2236-3459/60384

BARAUSSE, A. The construction of national identity in textbooks for Italian schools abroad: the case of Brazil between the two World War. History of Education \& Children's Literature, X (2), 425-461, 2015.

CHIOSSO, G. (Org). Il libro per la scuola tra Sette e Ottocento, La Scuola, Brescia, 2000.

CHIOSSO, G. (a cura di), TESEO. Tipografi e editori scolastico-educativi dell'Ottocento, Editrice Bibliografica, Milano, 2003.

CHIOSSO, G. Il rinnovamento del libro scolastico nelle esperienze di Giuseppe Lombardo Radice e dei «lombardiani», History of Education \& Children's Literature, I (2), 127-139, 2006.

CONSIGLIO SUPERIORE DI EDUCAZIONE. Sulle condizioni della pubblica istruzione nel regno d'Italia. Relazione generale presentata al Ministro dal Consiglio Superiore di Torino. Milano: Stamperia Reale. p. 543, 1865.

CONTINI, F. La questione dei libri di testo nelle Scuole della Libia. In A., Festa. La scuola italiana e l'opera di conquista morale della Libia. Tripoli: Maggi, 1932, p. 147 - 158. https://doi.org/10.30687/978-88-6969-281-9/009

DAMIANI Le scuole italiane nelle colonie d'America: circolare del sottosegretario agli Affari Esteri Abele Damiani. In: Ministero Affari Esteri. Annuario delle scuole coloniali per l'anno finanziario e scolastico 1889-1890. https://doi.org/10.2307/2608335

CIAMPI, G. Le scuole italiane all'estero. In V. Pellegrini (ed.). Amministrazione centrale e diplomazia italiana (1919-1943). Fonti e problemi. Roma: Istituto Poligrafico e Zecca dello Stato, 1998, p. 115 - 122.

DUGGAN, C. Creare la nazione. Vita di Francesco Crispi. Roma-Bari:Laterza, 2000.

Elenco dei libri di testo obbligatori per le regie scuole italiane all'estero. In: MINISTERO DEGLI AFFARI ESTERI. Annuario delle scuole italiane all'estero governative e sussidiate 1900. Roma: 1900, p. 83-128.

Elenco dei libri di testo obbligatori per le regie scuole italiane all'estero/a.s. 1900-901. In: MINISTERO DEGLI AFFARI ESTERI, Annuario delle scuole italiane all'estero governative e sussidiate 1901. Roma: 1901.

GENTILE, E. Fascismo, Storia e interpretazione. Roma-Bari, Laterza, 2002. 
FLORIANI, Giorgio. Scuole italiane all'estero: cento anni di storia. Roma: Armando Editore, 1974.

KREUTZ, L.; LUCHESE, T. Â. Grupos étnicos, pluralidade cultural e políticas públicas na história da educação no Rio Grande do Sul. In: Revista Brasileira de História de Educação, n. 11, n. 1, pp. 179-206, 2011. https://doi.org/10.4025/rbhe.v17n3.934

LA ROVERE, L. "Rifare gli italiani”: l'esperienza di creazione dell'uomo nuovo nel regime fascista. Annali di Storia dell'educazione e delle istituzioni scolastiche, 9, 51-58, 2002.

LEVRA, U. Fare gli italiani. Memoria e celebrazione del Risorgimento. Torino: Comitato di Torino dell'Istituto per la storia del Risorgimento italiano, 2002. https://doi.org/10.1086/ahr/86.3.615

SALVETTI, P. Le scuole italiane all'estero. In: Bevilacqua P., De Clementi A. e Franzina E. (a cura di). Storia dell'emigrazione italiana: Arrivi, Donzelli Roma. 2002. https://doi.org/10.1017/s1353294400014149

ORIANI, A. La legislazione fascista sulle scuole italiane all'estero. Torino: Paravia G.B. e C., 1926.

PORCIANI, I. Il libro di testo come oggetto di ricerca: i manuali scolastici nell'Italia postunitaria. In: Storia della scuola e storia d'Italia dall'Unità ad oggi. Bari: De Donato, 1982.

PORCIANI, I. L'industria dello scolastico. In: Ead. (a cura di), Editori a Firenze nel secondo Ottocento, Firenze: Olschki, 1983.

PORCIANI, I. Manuali per la scuola e industria dello scolastico dopo il 1860. In: TORTORELli, G. (Org). L'editoria italiana tra Otto e Novecento. Bologna: Edizioni Analisi, 1986.

PRETELLI M. Il fascismo e gli italiani all'estero. Bologna: Clueb, 2010.

MINISTERO DEGLI AFFARI ESTERI. Annuario delle Scuole coloniali per l'anno finanziario e scolastico 1888-1889. Roma: Tipografia di Gabinetto del Ministero degli Affari Esteri, 1889. https://doi.org/10.2307/2608335

MINISTERO DEGLI AFFARI ESTERI. Annuario delle Scuole Italiane all'Estero. Roma: Tipografia di Gabinetto del Ministero degli Affari Esteri, 1897. https://doi.org/10.2307/2608335

Reforma dos programas para as escolas elementares emanados com Carta Régia de 5 de setembro de 1888, $\mathrm{n}^{\circ} .5724$ ". Bollettino Ufficiale del Ministero dela Istruzione Pubblica, 1888, p. 492-512.

TABACCHI, E. Secondo i naturali confini della libertà degli insegnanti. Forme di censura e controllo nell'esperienza della seconda Commissione centrale per l'esame dei libri di texto. In: History of Education \& Children's Literature, vol. VIII, n. 2, 2013, pp. 239-258. 
VINÃO FRAGO, Antonio. Por una historia de la cultura escolar: cuestiones, enfoques, fuentes. Congreso de la Asociación de Historia Contemporanea, 3, 1998. Valladolid: Universidad de Valladolid, 1998, p. 167-183. https://doi.org/10.5944/hme.4.2016.16653

\section{REFERENCIAS ARQUIVÍSTICAS}

Circular do Ministro dos negócios exteriores de 10 de março de 1892 (minuta), Archivio Storico Diplomatico del Ministero degli Affari Esteri (ASMAE), AS, 1923-1928, b. 537.

Letter by Trabalza to Gaetano Cogo, central inspector of the Ministry of Public Education, October 18th, 1922. In ASMAE, AS, 1923-28, b. 537, f. Commissione per la scelta dei libri di cultura, di testo e per il materiale didattico per le scuole all'estero.. https://doi.org/10.2307/40236003

MINISTERO DEGLI AFFARI ESTERI. Elenco dei libri di testo obbligatori per le regie scuole italiane all'estero. Roma: 1899. In: ASMAE, AS, 1923-28, b. 537, s.f.Commissione per la scelta dei libri di cultura, di testo e per il materiale didattico per le scuole all'estero. https://doi.org/10.2307/40236003

MINISTERO DEGLI AFFARI ESTERI. Libri di testo per le scuole elementari. Esaminati dalla Commissione istituita con Decreto Ministeriale del 15 gennaio 1921. Roma: Stab. Tip. C. Colombo 1922, ASMAE, AS, 1923-1928, b. 537, s.f.Commissione per la scelta dei libri di cultura, di testo e per il materiale didattico per le scuole all'estero. https://doi.org/10.4000/diacronie.8318

Nota do presidente da comissão para o exame dos livros de texto, 6 de abril de 1880, em Archivio Centrale dello Stato, Ministero Pubblica Istruzione, Consiglio Superiore Pubblica Istruzione - 1849-1903, Atti versati posteriormente, I série, b. 5, f. 7. Libri di testo: relazioni e corrispondenza (1875-1884). https://doi.org/10.1017/cbo9781316151426.279

Pró-memória do Inspetor geral ao subsecretario do ministério dos negócios exteriores 12 de julho de 1889, ASMAE, AS, 1923-1928, b. 537, s.f. Commissione per la scelta dei libri di cultura, di testo e per il materiale didattico per le scuole all'estero. $\underline{\text { https://doi.org/10.2307/40069712 }}$

Pró-memória 13 de outubro de 1905, ASMAE, AS, 1923-28, b. 537, s.f. Commissione per la scelta dei libri di cultura, di testo e per il materiale didattico per le scuole all'estero. https://doi.org/10.2307/40236003

Relatorio Vittore Alemanni, La Scuola primaria italiana in Brasile, January 1923, ASMAE, AS, b. 1923-28, b. 702.

Relatório de P. Parini, 6 de junho de1930, ASMAE, AS (1929-1935), b. 1027 livros de texto.

Relatório Boselli, s.d. mas de 1924, ASMAE, AS, 1923-1928, b. 537, s.f. Commissione per la scelta dei libri di cultura, di testo e per il materiale didattico per le scuole all'estero.

Telegrama de 14 de Outubro 1927. ASMAE, AS 1929-1935, b. 1027. 


\section{LIVROS ESCOLARES}

ALFANI, A. Il sillabario del buon bambino, 8a ediz., Milano, Dabalà e Casaccia, 1897; Il primo libro del buon bambino, 5a ediz. Milano, Dabalà e Casaccia, 1895.

ALFANI A. Il libro di lettura per la 4a classe elem. 5a edizione interamente rifatta, corredata di numerose vignette. Firenze, R. Bemporad e figlio, 1898;

AUSONI Libero. Pensiero e volontá. Corso di letture per le scuole primarie italiane. Palermo: Sandron, 1905.

ALCUNI INSEGNANTI DEL MUNICIPIO DI TORINO. Lezioni di Geografia e Storia per le classi 3-6 elementari. Torino: Paravia s.d.

BACCI V. E GOTTI A.,Le glorie della patria (4a classe). 2a ediz. Roma, Soc. editr. Dante Alighieri, 1897.

BACCINI, I. Lezioncine di cose usuali. Torino, Paravia 1887.

BACCINI, I., Il primo anno di scuola. Letture educative per la prima classe elementare. Firenze R. Bemporad, 1894.

BERTOLINI, Francesco. Manuale illustrato di storia d'Italia ad uso delle scuole elementari (4a classe). Firenze, G. C. Sansoni, 1896.

BORDIGA Giovanni. Aritmetica pratica. Parte 3a. Venezia. M. Fontana, 1895.

BROCCHI Virgilio e GUSTARELLI Andrea Allegretto e Serenella, volumi per la 2,3,4 classe: Roma: Mondadori 1920.

CAMPAN, V. Consigli alle fanciulle, recati in italiano e pubblicati per cura di Pietro Thouar ad uso delle scuole elementari. Torino: Stamperia Reale della ditta G.B. Paravia 1888.

CAPPELLI BAJOCCO Marcellina, Api sui fiori, Milano, Mondadori, 1920.

CASTELLI Giuseppe,Letture per gli alunni della 4a classe elementare. 3a edizione. Roma, Società editrice Dante Alighieri, 1897. Letture per le alunne della 4a classe elem. 2a ediz. Roma, Società editrice Dante Alighieri, 1897; Castelli Giuseppe,Letture per gli alunni della 5a classe elem. 2a ediz. Roma, Società editrice Dante Alighieri, 1896. https://doi.org/10.1086/ahr/81.2.416

Letture per le alunne della 5a classe elem. 2a ediz. Roma, Società editrice Dante Alighieri, 1897.

CELLI, G., Sillabario per imparare la lettura contemporaneamente alla scrittura secondo il sistema fonico. Approvato dal Ministero della Pubblica Istruzione adottato nelle scuole comunali di Milano e nelle scuole di tutte le priincipali cittá d'Italia premiato alle esposizioni di Milano e di Torino. Milano: Giusepppe Celli, 1920. https://doi.org/10.2307/j.ctt1s476kg.13 
CIARLANTINI Franco e CAPODIVACCA Giovanni. Amore e Luce. Sillabario, compimento e corso di letture per le classi elementari. Milano: Nugoli, 1905.

COLLODI, C. Il Giannettino Libro per i ragazzi della quaarta classe elementare riordinato da Raffaello Mariani in conformitá dei vigenti programmi governativi. Firenze: R. Bemporad e Figlio concessionari della Libr. Ed. Felice Paggi, 1900.

COMBA, E. Testo atlante di geografia per le classi 4,5 e 6 elementare. Torino: Paravia, 1903.

CORTI, S. E CAVAZZUTI,P. Il bambino italiano alla scuola. Sillabario con molte incisioni. 5a ediz. Milano, A. Vallardi, 1895; La bambina italiana alla scuola. Sillabario. $8^{\text {a }}$ ediz. Milano, A. Vallardi, 1895.

CORTI S. E CAVAZZUTI P.,Il giovanetto italiano alla scuola. Libro di lettura per la classe $4^{\mathrm{a}}$, con molte incisioni due carte geografiche e due tavoli a colori, 3 a edizione. Milano, ecc, A. Vallardi editore, 1897.

CORTI S. e CAVAZZUTI P.,Il giovanetto italiano alla scuola. Libro di lettura per la classe $5^{\mathrm{a}}, 2^{\mathrm{a}}$ edizione con molte incisioni, Milano, ecc, A. Vallardi editore, 1896; Idem, La giovanetta italiana a scuola. Libro di lettura per la classe 5a. 2a ediz. con molte incisioni. Milano, ecc. A. Vallardi editore, 1896. https://doi.org/10.3280/rip2013-01006

COSTETTI BIAGI, E. Nuovo sillabario. Libro di testo per le scuole elementari del Comune di Firenze. Firenze: Paggi editore 1889.

CURAMI Giovan Battista Curami, Vita e patria. L'educazione morale e l'istruzione civile desunta dai brani dei piú accreditati scrittori scelti, collegati e coordinati allo scopo dal prof. G.B. Curami, Torino, Paravia 1905.

DAZZI PIETRO, Il libro per la $5^{\text {a }}$ classe elem. maschile, con numerose vignette. Nuova edizione interamente rifatta. Firenze, R. Bemporad e figlio, 1898.

DI GIUSTO,G. PASCIUTI, F., Cuor lontano. Sillabario e compimento. Torino: Paravia, 1921.

DI SAN GIUSTO, L. Italia nostra! Palermo: S. Biondo.

FORNACIARI, Nuova grammatichetta della lingua italiana. 2Firenze, G. C. Sansoni, 1897.

FERRARI L. Nuova grammatichetta della lingua italiana. 2 ediz. Parma, L. Battei, 1891.

FINO Saverio Fino e MATTANA Felice. Albe di vita Letture per le scuole elementari. Torino: Paravia, 1916.

FOCHI C. Avviamento allo studio della Geografia. Roma: Ermanno Loescher, 1888.

FRATTINI GIOVANNI,Aritemetica pratica. Parte 4a. Torino, G. B. Paravia, 1898. 
GABRIELLI, G. Primi affetti. Libro di lettura pei bimbi delle prime classi elementari a compimento del sillabario, compilato secondo i programmi governativi del 1888. Palermo: Remo Sandron 1889.

GROSSI MERCANTI, O.. Brevi racconti di storia patria dalla fondazione di Roma alla scoperta dell'America. Firenze, R. Bemporad, 1894.

GUELFI, C.L. Sangue italiano. Nuovissimo corso di letture speciali per le scuole italiane nelle colonie all'estero e nelle nuove terre redente, Firenze, Bemporad, s.d. [ma del 1920].

IRLANDI G. e NOLLETI F., Bontá e sapere. Sillabario e compimento. Torino: SEI, 1906,

MARCATI, G.A. In cammino fanciulli! Libro di lettura per le scuole elementari, Roma, Mondadori, 1911.

MARIANI, C. Grammatichetta italiana della lingua parlata. 4 ediz. Roma: Soc. edit. Dante Alighieri, 1896.

MERIGHI, G. Biografie e racconti di storia patria congiunti da nessi storici: ossia Nuovo compendio di storia italiana dai primi abitatori alla morte di Amedeo duca d'Aosta. Roma: Avvenire dei maestri d'Italia 188855 ed.

MESTICA-GALAMINI LUISA E MESTICA ENRICO, Libro di lettura per la quinta classe maschile. Fano: Società tip. cooper. 1898;

Libro di lettura per la quinta classe femminile. Fano: Società tip. cooper. 1898.

MORANDI L. e CAPPUCCINI, G. Grammatichetta italiana. Torino: G. B. Paravia, 1895.

ORLANDINI GRILLO, M. Nozioni di aritmetica conformi ai nuovi programmi governativi per le scuole elementari. Classe seconda. Milano: Tip. degli operai. 1889.

NOVELLI CLAUDIO, Corso elementare di grammatica francese ragionata, comparata all'italiano, ad uso delle scuole secondarie del Regno. Torino: Ditta G.B. Paravia, 1896.

PACINI, S. Piccola storia d'Italia : ad uso delle scuole elementari e ginnasiali inferiori. Cento racconti di Storia moderna Firenze: Paggi Editore, 4 ed. 1889.

PARLAGRECO, C. Grammatica elementare della lingua portoghese ad uso delle scuole italiane. Milano: Vallardi, 1919.

PINCHERLE, S., Gli elementi dell'aritmetica ad uso delle scuole elementari superiori. Bologna: N. Zanichelli, 1894.

Ministero I. P., Metodo per l'insegnamento del disegno (per la 4a e 5a classe).

PALAZZI. Romeo, Metodo per l'insegnamento del disegno di ornato ad uso delle scuole elementari e secondarie maschili e femminili. 
PLATA Alfredo e ARNAUD Luigi. Albor di vita: libri di lettura per la 5 e 6 elementare. Firenze: Bemporad, 1914.

POLI, G. E PERNICIARO, C. La grammatica italiana per le classi elementari superiori. Torino: Paravia, 1914.

RANDAZZO C. A Antologia poética compilata per le scuole elementari . Palermo: Stab. Tip. Giliberti 1884.

RANDAZZO, C. Lo Statuto del Regno d'Italia per le scuole elementari e domenicali, pei convitti e per gli operai. Palermo: Tip. del Gornale Il Tempo 1884.

ROSSI, G., Racconti illustrati di storia patria per la 4 classe elementare. Torino: Societá editrice internazionale, 1916, 2 ed..

SAFFRAY, C. Lezioni di cose. Prima traduzione italiana di Anna Garofoli Fumat, corredata di note storiche, scientifiche e pedagogiche da Lorenzo Bettini Torino: Ditta G. Paravia 1888.

SANTAMARIA FORMIGGINI, E. Prima lettura. Roma: A.F. Formiggini, 1917.

SCAGLIONE F.P. E FILIPPONI G. , Ometti e donnine. Letture educative. Libro di lettura per la 4a classe maschile. Nuova edizione riveduta e corretta, con acquerelli degli artisti Sarri e Tomaselli. Palermo, S. Biondo editore, 1899.

TARCHIANI, I. Manuale di amministrazione domestica per uso delle classi elementari e normali Roma: presso G.B. Paravia 1872.

TEGON, C. Frugolino. Libro di lettura, Milano, Casa editrice del Risveglio educativo, 1897.

TEGON, C., Libro di lettura per la classe 4a, illustrato da 70 incisioni. 31a ediz. Milano, Casa editrice del Risveglio educativo, 1898.

TOTI. G. La famiglia dell'artigiano. Avviamento alla lettura, primi mesi di scuola. Sillabario graduato a metodo fonico illustrato. Palermo: Sandron, 1887.

TOTI. G. Emma e Giulia alla prima classe elementare nei primi mesi di scuola. Sillabario graduato a metodo fonico illustrato. Palermo: Sandron, 1887.

TOTI. G. La famiglia dell'artigiano. Avviamento alla lettura, ultimi mesi di scuola. Compimento al sillabario illustrato. Palermo: Sandron, 1889.

VALLE P. Nozioni elementari di cosmografia e di geografia. Milano: Enrico Trevisini 1888.

VALLE. P., La cosmografia e la geografia insegnate agli alunni delle scuole elementari secondo le istruzioni e i programmi approvati con r. decreto 29 novembre 1894 . Vol $3^{\circ}$ per la quinta classe. Milano: Enrico Trevisini 1899.

VALLE.. P., La cosmografia e la geografia insegnate agli alunni delle scuole elementari secondo le istruzioni e i programmi approvati con r. decreto 29 novembre 1894 . Vol $2^{\circ}$ per la quarta classe elementare. Milano: Enrico Trevisini 1895. 
VENIALI, G., Corso di lettura per le scuole elementari maschili e femminili. Libro per la $4^{\mathrm{a}}$ classe. Torino, ecc, Ditta G.B. Paravia e Comp., 1898.

VENIALI, Giacomo. Corso di letture per le scuole elementari maschili e femminili. Libro per la 5a classe maschile. Torino ecc., Ditta G.B. Paravia e Comp., 1898.

VIANI VISCONTI CAVANNA, M.. Le sorellle. Libro di lettura per le bambine. 4 ed. Milano: Paolo Carrara 1887.

VISENTINI, O. Italia. Letture storiche per i fanciulli. Roma: Mondadori s.d.

VUGLIANO L.. I doveri dell'uoo e del cittadino, insegnati per via di esempi e di riflessioni morali in prosa ed in versi agli alunni ed alle alunne delle scuole elementari e popolari del Regno con appendice di alcune letterine. Torino: Grato Scioldo 1886.

ZANOTTI Leopoldina, Verso la luce. Sillabario e compimento, Firenze, Bemporad, s.d. [ma del 1915]. 